\title{
JNPH
}

Volume 6 No. 1 (April 2018)

(C) The Author(s) 2018

\section{IDENTIFIKASI KANDUNGAN BORAKS PADA MI BASAH DI PASAR TRADISIONAL KOTA BENGKULU}

\section{IDENTIFICATION OF BORAKS CONTAINERS IN WET MI IN TRADITIONAL MARKET OF BENGKULU CITY}

\author{
PUTRI WIDELIA, JON FARIZAL, DAN MULA NARTI \\ POLITEKNIK KESEHATAN KEMENTERIAN KESEHATAN BENGKULU \\ PRODI DIII ANALIS KESEHATAN
}

\begin{abstract}
ABSTRAK
Latar Belakang : Mi basah (mi basah mentah atau mi basah matang) merupakan salah satu jenis mi yang sudah dikenal luas dan menjadi makanan yang disukai masyarakat di Indonesia. Penggunaan boraks masih tinggi berdasarkaan data dari BPOM Bengkulu. Indonesia menempati urutan kedua setelah korea. Industri mi basah tersebar luas di berbagai wilayah di Indonesia dan kebanyakan diproduksi oleh industri rumah tangga, dan industri kecil atau menengah. Penggunaan boraks ini pada makanan karena asam borat dapat menghambat pertumbuhan dari mikroorganisme,sehingga makanan yang telah ditambahkan boraks ini terlihat segar dan awet tahan lama. Penelitian ini bertujuan untuk mengidentifikasi ada tidaknya boraks pada mi basah di Kota Bengkulu tahun 2017. Tujuan Penelitian: Untuk mengidentifikasiadatidaknyaborakspada mi basah yang di jualdipasartradisional Kota Bengkulu Tahun 2017. Metode : Metode penelitian ini adalah uji kualitatif metode uji kertas kurkuma, sampel dalam penelitian ini adalah $33 \mathrm{mi}$ basah yang dijual di pasar tradisional Kota Bengkulu dengan teknik pengambilan sampel simplerandom sampling.Hasil :Hasil penelitian dari 33 mi basah yang dijual dipasar tradisional Kota Bengkulu, ditemukan sebagian besar $22(66,66 \%) \mathrm{mi}$ basah yang mengandung boraks. Pada metode kurkuma, sampel yang positif mengandung boraks, dengan warna cokelat kemerahan atau merah bata. Ciri-ciri mi basah yang mengandung boraks yaitu teksturnya kenyal, lebih mengkilat, tidak lengket, dan tidak cepat putus.Kesimpulan :Sebagian besar $(66,66 \%)$ ditemukannya boraks pada mi basah yang dijualdipasar tradisional Kota Bengkulu. Sehingga perlu dilakukan sosialisasi dari Dinkes kepada pedagang tentang bahayanya boraks, dan dapat meminimalisir penggunaan boraks oleh pedagang mi basah.
\end{abstract}

Kata Kunci :boraks, mi basah, kualitatif

\begin{abstract}
Background: Wet noodles (raw wet noodles or wet noodles) are one of a kind of noodles that are widely known and favored by Indonesian. The use of borax is still high based on POM Bengkulu. Indonesia ranks is second after korea. The wet noodle industry is widespread in many parts of Indonesia and is mostly produced by home industries, and small or medium industries. The use of this borax in foods because boric acid can inhibit the growth of microorganisms, so the food has been added borax looks fresh and durable lasting. This study aims to identify the presence or absence of borax in wet noodles in the city of Bengkulu
\end{abstract}


2017.Research Objectives: To identify at least the wet noodle slippers sold in traditional Bengkulu City 2017.Method: This research method is qualitative test of kurkuma paper test method, the sample in this research is 33 wet noodles sold in traditional market of Bengkulu City with sampling technique of simplerandom sampling.Result: Result of research from 33 wet noodles sold in traditional market of Bengkulu City, found most of $22(66,66 \%)$ wet noodle containing borax. In the kurkuma method, a positive sample contains borax, with reddish brown or red brick. The characteristics of wet noodles that contain borax texture is chewy, more shiny, not sticky, and not quickly broken.Conclusion: Most $(66.66 \%)$ found the borax on wet noodles sold in traditional markets of Bengkulu City. So it is necessary to socialize from Dinkes to traders about the danger of borax, and can minimize the use of borax by wet noodle traders.

\section{Keywords: borax, wet noodle, qualitative}

\section{PENDAHULUAN}

Peningkatan jumlah penduduk menyebabkan kebutuhan bahan makanan akan semakin meningkat ditandai dengan munculnya berbagai variasi produk makanan yang lebih awet, menarik, dan menguntungkan. Saat ini ditemukan berbagai produk makanan yang diberi bahan tambahan berupa bahan penyedap, pewarna dan pengawet yang berbahaya. Dugaan adanya kandungan pewarna tekstil, formalin dan boraks dalam beberapa produk makanan terutama jajanan dipinggir jalan dan dipasar seperti bakso, sosis, siomay yang digunakan untuk mengenyalkan dan membuat warna lebih bersih. Badan Pemeriksa Obat dan Makanan (BPOM) serinng melakukan sidak ke berbagai tempat dan menemukan beberapa makanan yang diberi bahan tambahan boraks (5)

Salah satu makanan yang populer di masyarakat Indonesia adalah mi. Mi yang tersedia pun beraneka ragam jenisnya, ada yang berbahan dasar mi basah dan ada yang berbahan dasar mi kering. Mi basah (mi basah mentah atau mi basah matang) merupakan salah satu jenis mi yang sudah dikenal luas dan menjadi makanan yang disukai masyarakat di Indonesia. Saat ini Indonesia menempati urutan kedua pengkosumsi mi terbesar di dunia setelah Korea. Industri mi basah tersebar luas di berbagai wilayah di Indonesia dan kebanyakan diproduksi oleh industri rumah tangga, dan industri kecil atau menengah.

\section{Bahan Tambahan Pangan yang}

selanjutnya disingkat BTP adalah bahan yang ditambahkan kedalam pangan untuk mempengaruhi sifat atau bentuk pangan. Dalam Kehidupan sehari-hari, BTP telah digunakan oleh produsen pangan sebagai bahan pembantu pengolahan pangan. Namun, kenyataan dilapangan menunjukkan bahwa sampai hari ini masih dijumpai produsen pangan yang menggunakan bahan kimia yang dilarang $(7)$

Konsumsi boraks berlebih dengan kadar mencapai $2 \mathrm{~g} / \mathrm{Kg}$ dapat menyebabkan keracunan, dapat menimbulkan beberapa gejala, yaitu: iritasi kulit dan saluran pernapasan, gangguan percernaan seperti mual, muntah persisten, nyeri perut dan diare, gejala keracunan yang berat dapat menyebabkan ruam kulit, penurunan kesadaran, depresi napas bahkan gagal ginjal. Penelitian di Malaysia tahun 1988 kasus keracunan boraks pernah dilaporkan setelah mengkonsumsi mie, juga di Bengkulu tahun 2011 dikabarkan warga keracunan makanan yang diduga mengandung boraks. Oleh karena efek toksisitasnya, banyak negara yang telah melarang penambahan boraks pada makanan seperti Inggris, Thailand, China, Malaysia, terutama di Indonesia, sehingga Pemerintah mengeluarkan peraturan larangan penggunaan boraks sebagai bahan tambahan pangan pada Peraturan Menteri Kesehatan RI No.033/Menkes/Per/IV/2012 tentang Bahan Tambahan Pangan, BTP hanya boleh digunakan tidak melebihi batas maksimum penggunaan dalam kategori pangan ${ }^{(1)}$ 


\section{TUJUAN PENELITIAN}

Untuk mengidentifikasi ada tidaknya boraks pada mi basah yang dijual di pasar tradisional Kota Bengkulu tahun 2017.

\section{METODE PENELITIAN}

Metode penelitian ini adalah uji kualitatif metode uji kertas kurkuma. Penelitian ini telah dilaksanakan di Laboratorium Poltekkes Kemenkes Bengkulu pada bulan November 2016 - Februari 2017. Sampel penelitian ini diambil dengan metode Simple Random Sampling yang terdiri dari 49 orang pedagang mi basah yang dipilih secara acak menggunakan angka acak.

\section{HASIL PENELITIAN}

Hasil analisis penelitian identifikasi kandungan boraks pada mi basah di pasar tradisional Kota Bengkulu dilakukan pada 33 pedagang dengan hasil distribusi frekuensi mi basbah yang disajikan pada tabel 4.1 di bawah ini.

Tabel 1. Distribusi frekuensi mi basah berdasarkan kandungan boraks di Pasar tradisional Kota Bengkulu tahun 2017

\begin{tabular}{cccc}
\hline No & Mi basah & Jumlah & Persentase \\
\hline 1. & Mengandung boraks (+) & 22 & $66,66 \%$ \\
\hline 2. & $\begin{array}{c}\text { Tidak mengandung } \\
\text { boraks }(-)\end{array}$ & 11 & $33,34 \%$ \\
\hline 3. & Total & 33 & $100 \%$ \\
\hline
\end{tabular}

Dari tabel 1 diatas, ditemukaan mi basah yang mengandung boraks terdapat 22 sampel (66.,66\%) yang dinyatakan positif mengadung boraks. Artinya sebagian besar mi basah yang dijual dipasar tradisional Kota Bengkulu mengandung boraks. Persentase ini lebih tinggi dibandingkan dengan penelitian sebelumnya yang dilakukkan di Depok dari 20 sampel dengan persentase 31\%. Dan penelitian juga dilakukan di Kota Manado dari 5 sampel dengan persentase $60 \%$ pada uji nyala.
Tabel 2 persentase mi basah yang mengandung boraks berdasarkan nama pasar tradisional Kota Bengkulu tahun 2017

\begin{tabular}{ccccc}
\hline No & $\begin{array}{c}\text { Nama } \\
\text { Pasar }\end{array}$ & $\begin{array}{c}\text { Jumlah } \\
\text { sampel }\end{array}$ & $\begin{array}{c}\text { Jumlah } \\
\text { sampel } \\
\text { positif }\end{array}$ & $\begin{array}{c}\text { Persentase } \\
\text { positif (\%) }\end{array}$ \\
\hline 1. & A & 7 & 4 & 57,14 \\
\hline 2. & B & 6 & 4 & 66,66 \\
\hline 3. & C & 6 & 4 & 66,66 \\
\hline 4. & D & 5 & 4 & 80 \\
\hline 5. & E & 4 & 2 & 50 \\
\hline 6. & F & 5 & 4 & 80 \\
\hline
\end{tabular}

Dari tabel 2 Berdasarkan tabel diatas ditemukan persentase mi basah paling tinggi ditemukan di 2 pasar yaitu pasar kaget dan pasar baru koto sebesar $80 \%$.

\section{PEMBAHASAN}

Berdasarkan uji laboratorium yang telah dilakukan di Laboratorium Terpadu Poltekkes Kemenkes Bengkulu terhadap 33 sampel, terdapat $22(66,66 \%)$ sampel yang dinyatakan positif mengandung boraks dengan jumlah sampel setiap pasar yang berbeda. Dari hasil penelitian dapat disimpulkan bahwa di Bengkulu penggunaan boraks sebagai bahan tambahan pangan masih tinggi. Hal ini ditunjukkan dengan hasil penelitian yang dilakukan tidak ada satupun pasar yang bebas dari penggunaan boraks sebagai bahan tambahan pangan.

Sampel yang positif mengandung boraks, dengan warna cokelat kemerahan atau merah bata. Cara kerja pengujian ini menggunakan kertas kunyit. Ekstrak kunyit dapat digunakan sebagai pendeteksi boraks karena ekstrak kunyit tersebut mengandung senyawa kurkumin. Kurkumin dapat mendeteksi adanya kandungan boraks pada makanan karena kurkumin mampu menguraikan ikatan-ikatan boraks $\left(\mathrm{Na}_{2} \mathrm{~B}_{4} \mathrm{O}_{7}\right.$. $\left.10 \mathrm{H}_{2} \mathrm{O}\right)$ menjadi asam borat $\left(\mathrm{H}_{3} \mathrm{BO}_{3}\right)$ dan mengikat warna atau yang biasa disebut dengan senyawa boron cyano kurkumin kompleks. Ketika makanan yang mengandung 
boraks ditetesi oleh ekstrak kunyit akan mengalami perubahan warna menjadi warna merah kecoklatan ${ }^{(2)}$

Boraks tidak boleh digunakan dalam makanan berdasarkan Peraturan Menteri Kesehatan RI No.033/Menkes/Per/IV/2012 tentang bahan tambahan pangan, jenis bahan tambahan pangan golongan pengawet yang dilarang penggunaannya dalam produk pangan salah satunya yaitu asam borat. Asam borat dalam keseharian nya digunakan sebagai pembersih, fungisisda, herbisisda dan insektisisda yang bersifat toksik pada manusia (6)

Penelitian ini sejalan dengan penelitian sebelumnya yang pernah dilakukan pada mie basah yang dijual dikota Manado didapatkan hasil dari 5 sampel, terdapat 3 sampel yang dinyatakan positif mengandung boraks pada uji nyala dengan warna hijau kekuningan, dengan persentase $60 \%$ sedangkan pada uji kertas kurkuma terdapat 5 sampel yang positif mengandung boraks dengan warna yang menunjukkan kertas berubah warna menjadi orange kemerahan, dengan persentase $100 \%$ (4) Penelitian mie basah juga pernah dilakukan di depok secara kualitatif dengan reaksi reagen, terjadi perubahan warna kuning, pada kertas uji menjadi merah kecoklatan atau merah bata.didapatkan hasil dari 20 sampel yang dilakukan pengujian terdapat 11 sampel yang positif dari 4 mi basah mentah dengaan jumlah sampel $9 \mathrm{mi}$ basah mentah dan $7 \mathrm{mi}$ basah matang yang positif. Sebanyak $31 \% \mathrm{mi}$ basah mentah dan seluruh mi basah matang $(100 \%)^{(2)}$

Ciri - ciri mi basah yang mengandung boraks yaitu, tekstur nya yang kenyal, lebih mengkilat tidak lengket dan tidak cepat putus (Habsah 2012). Ciri ciri mi basah yang peneliti temukan dalam penelitian adalah teksturnya kenyal, lebih mengkilat, tidak lengket, dan tidak cepat putus, bau menyengat. Bahan-bahan ini dapat terakumulasi pada tubuh manusia dan bersifat karsinogenik yang dalam jangka panjang dapat menyebabkan penyakit kanker dan tumor terhadap tubuh yang mengkosumsi boraks $(3)$

\section{KESIMPULAN}

Penggunaan boraks pada makanan masih tinggi, dibuktikan dengan ditemukannya sebagian besar mi basah yang dijual di pasar tradisional Kota Bengkulu yakni sebesar $66,66 \%$.

\section{SARAN}

Bagi masyarakat Sebagai informasi kepada masyarakat bahwa mi basah yang dijual di pasar tradisional Kota Bengkulu mengandung boraks.

Bagi instansi terkait Perlu adanya sosialisasi pemerintah dari DINKES dan BPOM Kota Bengkulu kepada pedagang mi basah tentang bahayanya boraks. Agar dapat meminimalisir penggunaan boraks oleh pedagang mi basah.

Bagi ilmu pengetahuan Memberikan informasi dan pengetahuan bagi pembaca khusunya yang berhubungan dengan borakas pada mie basah.

Bagi institusi pendidikan Sebagai referensi untuk Mahasiswa dan dapat dijadikan acuan untuk melakukan penelitian selanjutnya di masa yang akan datang dengan variabel penelitian yang berbeda

\section{DAFTAR PUSTAKA}

Fuad, nur rohimah. 2014. "Identifikasi Kandungan Boraks Pada Tahu Pasar Tradisional Di Daerah Ciputat." : 1319.

Habsah. 2012. "Gambaran Pengetahuan Pedagang Mi Basah Terhadap Perilaku Penambahan Boraks Dan Formalin Pada Mi Basah Dikantin Kantin Universitas X Depok." : 18-39.

Ilza, Mirna. 2012. "Analisis Kandungan Boraks Pada Jajanan Bakso Tusuk Di Sekolah Dasar Di Kecamatan Bangkinang Kabupaten Kampar." : 134-45.

Payu, Muzdalifah, Jemmy Abidjulu, and Citra 
Gayatriningtyas. 2014. "Analisis Boraks Pada Mie Basah Yang Dijual Di Kota Manado." 3(2): 73-76.

Sari, lupi ratna. 2014. "Analisa Air,makanan,dan Minuman Analisa Boraks." : 1-17.

Suntaka, dwi fitri. 2014. "Peran Bahan Tambahan Pangan Ramai-Ramai Menggunakan Bahan Tambahan Formalin Dan Boraks . Hal Ini Bertujuan Untuk Berdasarkan Uji Terbatas Terhadap Sampel Bakso Yang Dilakukan Secara Mandiri Pada Bulan Maret 2014 Di Kios Bakso Permanen Penting Sejalan Deng." : 39-45.

Triatama, joni. 2014. "Identifikasi Kandungan Boraks Pada Keripik Usus Ayam (Berizin) Yang Dijual Di Pasar Besar Kota Kuala Kapuas Kalimantan Tengah.” : 15-21. 